\title{
The creation of a grey literature database for the British Columbia Environmental and Occupational Health Research Network (BCEOHRN): lessons learned and next steps
}

\author{
Megan Wiebe
}

\section{Introduction}

This paper outlines the steps that led to the creation of a grey literature database for the British Columbia Environmental and Occupational Health Research Network (BCEOHRN), particularly an MLIS student's involvement in the project during the summer of 2006. The paper makes suggestions for the continued involvement of a professional health librarian as the project grows in size and importance for BCEOHRN researchers.

BCEOHRN is one of eight networks funded by the Michael Smith Foundation in early 2005, as part of its Networking Infrastructure Program. Its aim is to "build capacity, facilitate and enhance B.C.'s ability to address health issues, and align health research in the province with national and international research and funding priorities to improve competitiveness for external funding" [1]. As part of this initiative, BCEOHRN works specifically to support research in occupational and environmental health in British Columbia.

The scientific director of BCEOHRN, Dr. Susan Kennedy, a professor in the School of Environmental and Occupation Hygiene at the University of British Columbia, ambitiously supports new and innovative initiatives to put BCEOHRN at the forefront of the eight networks. One of the network's goals for 2006 was to create an environmental and occupational health-related grey literature database, which led to the author's involvement in the project.

\section{BCEOHRN mission and vision}

The primary objective of BCEOHRN is to develop and improve the research community in occupational and environmental health within the province of British Columbia. Specifically, BCEOHRN's mandate is to support British Columbia researchers by

(i) Providing opportunities for "training, research development, and communications" [2]

M. Wiebe. School of Library, Archival and Information Studies, University of British Columbia. Present address: 812 West 14th Avenue, Vancouver, BC V5Z 1R1, Canada (e-mail: megwiebe@gmail.com). (ii) Facilitating collaborative research projects

(iii) Focusing on "key occupational and environmental health risks confronting British Columbians" [2]

(iv) Helping "B.C. researchers become or remain nationally and internationally competitive in acquiring research funding" [2]

(v) Encouraging students to pursue research careers in environmental and occupational health

(vi) Ensuring easy and efficient access to information and resources in environmental and occupational health

(vii) Promoting "better knowledge of the capacity, expertise, and opportunities existing in the province" [2]

\section{BCEORHN grey literature database}

The grey literature database is one of many initiatives undertaken by BCEORHN since its formation 2 years ago to fulfill its mandate of supporting British Columbia research and researchers. During the summer of 2006, BCEOHRN hired a library school student from the University of British Columbia on contract to locate relevant grey literature and enter citations (or the grey literature itself) into a database. Since BCEOHRN has no physical space, it was intended that the database would be composed of full-text documents accessible through the Internet or stored as PDF documents.

The scope of the project was initially limited in an effort to keep it at a manageable size for the student. The main inclusion criterion was that the documents were produced between 1990 and the present by British Columbia researchers. Furthermore, it was important to the board of directors that the approximately 350 network members were well represented in the database. Consequently, the data collection methods fell into two categories:

(1) Contacting all network members to request contributions of grey literature that either they had produced or they felt would have value to their fellow members Grey literature that was available only in hard copy was scanned and converted into PDF format to be accessible electronically.

(2) Searching the Web for relevant grey literature - This included government Web sites, nongovernmental organi- 
zations, institutional repositories, and educational institutes.

\section{Challenges}

Because of the project's originality, there were no models or guidelines to follow; the development of this database was new to everyone involved. Accordingly, there were various challenges associated with the successful completion of the database:

(1) Although network members were very supportive and enthusiastic and deemed it important for themselves to contribute to the grey literature database, most were too busy to spend time combing their files for grey literature. When contacted by the author, many members indicated that they had grey literature to contribute but did not follow through with sending the material, even after follow-up communications. Most of the grey literature created by network members and contained in the database was found on the Internet by the student.

(2) The creation of the actual database was problematic from the beginning, partially owing to the demand for employees in this industry. Therefore, the project fell significantly behind the initially predicted completion date of August 2006. Some consequences of this delay were the necessity of migrating a large amount of data and files into the database and the ability of the student to work a limited number of hours during the school year. The database finally went live in February 2007.

(3) As the student was new to grey literature and was working on this project independently with minimal guidance from the board of directors, it was challenging to determine and implement an effective search strategy for locating full-text grey literature online. To resolve this difficulty, the student met with librarians at the University of British Columbia and WorkSafe BC for guidance. The author also did independent research on grey literature and where and how to find it.

\section{Grey literature in scientific research: importance and challenges}

When conducting scientific research, it is vitally important to include grey literature in the literature review in addition to peer-reviewed journal articles so that the results and conclusions can be as accurate and comprehensive as possible. Since grey literature does not conform to any rules or guidelines, it has the flexibility to provide extensive detail when necessary and thus place the research in a wider context.

As Weintraub states, "grey literature, covering nearly every aspect of the sciences, serves scholars and lay readers alike with research summaries, facts, statistics, and other data that offer a more comprehensive view of the topic of interest" [3]. Grey literature is useful for "providing context for findings contained in commercial sources" [4]. According to Alberani, the most widely used types of grey literature are technical reports (particularly those produced in the US, UK, and Canada), theses, and conference proceedings [5].

It is particularly vital to include grey literature when conducting systematic reviews or meta-analyses. Meta-analyses need to include grey literature to "fully reflect the existing evidential base" of the clinical issue under review [6]. The consequences of not including grey literature are "exaggerated estimates of intervention effectiveness" [7], an overrepresentation of studies with statistically significant findings, and inflated "effect size estimates" [6]. The inclusion of grey literature also reassures the research team that the work they are doing is comprehensive [8].

Grey literature is difficult to find because of its unpublished and unindexed status, its minimal distribution, and because it is buried in the deep Web or available only in hard copy. Other challenges of working with grey literature include the heterogeneity of grey literature documents and the increased cost of searching due to the workload involved (e.g., finding the same study described in a peer-reviewed journal as well as a grey literature document) [8]. To improve access to this important resource, Banks suggests that we must "develop bibliographic resources of comparable depth as those available for the peer-reviewed literature" [9].

\section{Librarian's role}

Grey literature is available to those who can find it. Health librarians with expert search skills are at a considerable advantage when conducting this type of research. Giustini suggests that any document in the information age is grey until it is found; the "greyness" of a document is becoming more a characteristic of the mode of access and not of the item itself [10].

Because finding grey literature requires specialized knowledge and skills, and librarians generally have this expertise, it is important that they be part of the scientific research process. "Effective searching of the grey literature is a professional skill usually undertaken by information specialists. The aim of this searching is to be thorough and to optimize recall but with sufficient precision" [11]. This is particularly vital in areas of medicine and health, where flawed research can have fatal consequences.

\section{Conclusion}

Grey literature searching is a specialized skill and is usually performed by health librarians. It is a valuable and arguably essential component of most scientific research, particularly in the systematic review, meta-analysis, or other comprehensive methods of information retrieval. The challenges involved in locating grey literature effectively and efficiently make it an ideal task for health librarians or information professionals, and they should be included as part of research teams. While health librarians possess the technical information retrieval skills, research team members are experts in the subject domain being studied. Together they can (1) point the librarian towards key authors, resources, and organizations; and (2) define their information needs in detail.

While the success of the BCEOHRN grey literature database cannot be judged prematurely, the creation of the database was unquestionably a satisfying accomplishment. Many challenges were overcome, and those involved in the project gained considerable knowledge and experience. The author gained an expert knowledge of grey literature, while BCEOHRN gained a valuable resource for its members. This database adheres to the network's goals of improving re- 
search in environmental and occupational health in British Columbia. Furthermore, as an ongoing project, the database will continue to grow, expand, adapt, and change in response to the needs of its members.

\section{References}

1. Michael Smith Foundation for Health Research [homepage on the Internet]. Vancouver, B.C.: Michael Smith Foundation; [updated 2006 Feb 1; cited 2006 Nov 20]. Funding programs; [about 2 screens]. Available from www.msfhr.org/sub-fundingnetwork.htm.

2. British Columbia Environmental and Occupational Health Research Network [homepage on the Internet]. Vancouver, B.C.: BCEOHRN; [updated 2006 Aug 9; cited 2006 Nov 20]. Mission and vision; [about 2 screens]. Available from www.bceohrn.ca/about-mission.html.

3. Weintraub I. The role of grey literature in the sciences. Access Brooklyn College Library and AIT E-Zine. 2000 Fall;10: [about 4 screens]. Available from http://library.brooklyn.cuny.edu/ access/greyliter.htm.

4. Haig A, Dozier M. BEME guide no 3: systematic searching for evidence in medical education - Part 1: sources of information. Med Teach. 2003 July;25(4):352-63.
5. Alberani V, Pietrangeli PDC, Mazza AMR. The use of grey literature in health sciences: a preliminary survey. Bull Med Libr Assoc. 1990 Oct;78(4):358-63.

6. Conn VS, Valentine JC, Cooper HM, Rantz MJ. Grey literature in meta-analyses. Nurs Res. 2003 Jul/Aug;52(4):256-61.

7. McCauley L, Pham B, Tugwell P, Moher D. Does the inclusion of grey literature influence estimates of intervention effectiveness reported in meta-analyses? Lancet. 2000 Oct 7;356:1228-31.

8. Benzies KM, Premji S, Hayden A, Serrett K. State-of-theevidence reviews: advantages and challenges of including grey literature. Worldviews Evid Based Nurs. 2006;2:55-61.

9. Banks M. Connections between open access publishing and access to gray literature. J Med Libr Assoc. 2004 Apr;92(2):164-66.

10. Giustini D. UBC academic search: Google scholar blog [blog on the Internet]. Vancouver, B.C.: D. Giustini; [updated 2006 Oct 5; cited 2006 Nov 20]. The Web's deep, dark edge - finding grey literature; [about 1 screen]. Available from http://weblogs. elearning.ubc.ca/googlescholar/archives/031841.html.

11. UBC HealthLib-Wiki - a knowledge-base for health librarians (2006) [wiki on the Internet]. Vancouver, B.C.: D. Giustini; [updated 2006 Oct 20; cited 2006 Nov 20]. Grey literature; [about 25 screens]. Available from http://hlwiki.slais.ubc.ca/ index.php?title=Grey_literature. 
